\title{
OČUVANJE AUTENTIČNOSTI KULTURNOG NASLEĐA U PROCESU DIGITALIZACIJE
}

\author{
Verica Bulović1, \\ Marija Najdić2 \\ 'Smart Agency, \\ Subotica, Srbija \\ ${ }^{2}$ Visoka turistička škola strukovnih studija, \\ Beograd, Srbija
}

\begin{abstract}
Rezime:
Sve je veći broj broj muzeja i kulturnih atrakcija koje koriste digitalne tehnologije kao platformu za pružanje informacija o lokalitetima i kulturnoj baštini. Prvi kontakt savremenog posetioca sa kulturnom baštinom je upravo preko interneta. Aplikacije kao što su sistemi mobilnih vodiča, planeri za putovanje, internet portali i 3D aplikacije podržavaju iskustvo potrošača prlikom posete. Pored toga, mobilne i 3D aplikacije omogućavaju da korisnici lakše razumeju složene kulturne fenomene kroz učenje koje ima zabavni karakter. U radu se istražuje povezanost procesa digitalizacije kulturnog nasleđa i očuvanja autentičnosti. Autentičnost digitalnog nasleđa odnosi se na pouzdanost zapisa i kvalitet sadržaja koji bi trebalo da ga predstavlja. Digitalne tehnologije mogu uticati na kvalitet prenosa informacija i iz tog razloga pristupilo se kvalitativnom istraživanju putem intervjua sa stručnjacima u vezi autentičnosti objekata kulture s obzirom na sprovedenu digitalizaciju. Rezultati istraživanja su pokazali da se autentičnost kulturnog nasleđa u procesu digitalizacije smatra izuzetno važnom s tačke gledišta kustosa muzeja koji su učestvovali u istraživanju.
\end{abstract}

Ključne reči:

kulturno nasleđe, digitalne tehnologije, autentičnost, virtuelni muzej, mobilne aplikacije

UVOD

Danas, kultura i kulturno nasleđe predstavljaju najvažniju osnovu za kreiranje i održavanje vrednosti identiteta i pripadnosti zajednici. Digitizacija kulturnog nasleđa i upotreba veb-a pružaju šansu kulturnim institucijama da privuku što više posetilaca, s obzirom da se trenutno nalaze u poziciji da se moraju takmičiti u okruženju koje je pod dejstvom tržišnih sila. Ovo okruženje podrazumeva i nužan prelazak na novu "kulturnu ekonomiju" koju karakteriše pristupnost korisničkom servisu.

Digitalizacija kulturnog nasleđa doprinosi marketingu kulturnih institucija omogućavajući im da potrošačima ponude vrednost koju traže i pomaže u izgradnji odnosa između potrošača i institucija. Način na koji se ostvaruje kulturno iskustvo se nije mnogo promenio kroz vekove unazad. Međutim, poslednjih godina, a naročito sa pojavom i sve većim korišćenjem pametnih telefona i tableta u svakodnevom životu, zahtevaju se novi načini izlaganja kulturnog materijala.
Correspondence:

Verica Bulović

e-mail:

bveruska74@gmail.com 
Ovi novi načini mogu transformisati restriktivno okruženje muzeja tako da pasivni objekat koji posetioci posmatraju postane aktivni subjekt koji može da obezbedi nove informacije, neku vrstu hiperveze za pristupanje dodatnim informacijama.

Digitalni alati povećavaju dostupnost kulturne baštine i umanjuju udaljenost između ljudi i kulturno-istorijskih spomenika. Proces digitalizacije kulturnog nasleđa povezan je sa autentičnošću predstavljanja objekta posetiocima. Autentičnost je neodvojivi kvalitet objekta kulture, izložbe ili koncerta, dok digitalne tehnologije služe kao pomoć u njihovom predstavljanju. Iz razloga što se digitalizacija odnosi na reprodukciju fizičkih objekata u elektronskom obliku, može doći do raznih vrsta manipulacije te se javljaju pitanja u odnosu na autentičnost. Ovaj rad ima nameru da istraži (1)na koji način digitalne tehnologije mogu pomoći posetiocima da dožive autentičnost atrakcije i iskustvo povodom toga i (2)koju ulogu imaju digitalne tehnologije u predstavljanju kulturne atrakcije posetiocu.

\section{TEORIJSKE OSNOVE}

Koncept kulturnog nasleđa je čvrsto vezan za kulturni program savremenog društva. Definicija kulturnog turizma se razvijala od inicijalne vizije koja je ograničena na kretanje ljudi koje je uslovljeno obilaskom kulturnih atrakcija izvan mesta stanovanja (Richards, 1996; Whyte et al, 2012), da bi se potom uključio i širi spektar od kulturnih, istorijskih i prirodnih dobara, kao što su nematerijalni elementi kulture, mesta, atrakcija i događaja ( Russo \& Jansen-Verbeke, 2008; Di Pietro et al, 2015). Na primer, gastronomski turizam predstavlja jedan od najznačajnijih sektora kulturnog turizma Kulturno nasleđe obuhvata „ materijalna dobra, kao što su spomenici kulture, arheološka nalazišta ili skulpture i nematerijalna ulaganja kao što su usmene tradicije, izvođačke umetnosti i rituali" (UNESCO, 2015). Turizam kulturnog nasleđa može biti spona za integraciju ljudi, nacija, ekonomija i tradicija (Seppe \& Di Trapani, 2010) i doprinosi povećanju razumevanja kulturnih vrednosti i identiteta.

Implementacija inovativnih načina doživljaja kulturnog nasleđa ima potencijal da privuče nove segmente turista. Važan element ovog razvoja je internet, koji se iz informativnog medija pretvorio u komunikacionu platformu. Iz toga su proizašle razne digitalne tehnologije koje imaju osobinu interaktivnosti sa posetiocima, multimedijalnu orjentaciju i mogu biti personalizovane, što znači da se mogu prilagoditi potrebama različitih korisnika (Thomas et al, 2010). Za veb i mobilne aplikacije nema prostornog i vremenskog ograničenja, a posebna prednost se odnosi i na to što se mogu koristiti na više svetskih jezika. Pored toga, postoji neograničena mogućnost povezivanja sa drugim sistemima kao što su sistemi za bukiranje smeštaja, sa velikim turoperatorima ili savetnicima za putovanja. Neke od najznačajnijih digitalnih tehnologija koje se koristite u marketingu kulturnog turizma će biti ukratko objašnjene.

Veb platforma je postala već uobičajen prvi kontakt posetioca sa kulturnom atrakcijom. Preko veb stranice predstavljaju se kulturno-istorijski spomenici, muzeji ili manifestacije. Na internet prezentaciji gradova mogu se naći informacije o najvažnijim mestima koje treba posetiti ili najava kulturnih dešavanja.

Mobilne aplikacije su prilagođeni prikazi relevantnih turističkih sajtova manjim monitorima (tableti i telefoni), što ih čini korisnijim za posetioce. Prednost mobilnih uređaja je što su lako prenosni, dostupni i jednostavni za korišćenje, koriste ih i razne starosne grupe, a novijim generacijama su postali sastavni deo života.

Virtuelna realnost (VR) i 3D aplikacije obično pokazuju deo stvarnog sveta, dopunjuju ili stvaraju nove virtuelne svetove u kojima jedan ili više učesnika mogu istovremeno učestvovati. Ovo uključuje, na primer, augmentativnu stvarnost (AR) i geocaching (Smith, 2014). Na mobilnim uređajima digitalni sloj je postavljen na fizički svet u realnom vremenu. Kao jedan od najpoznatijih primera primene VR u promociji kulturnih sadržaja možemo navesti „Metropolitan muzej“ umetnosti u Njujorku i projekat pod nazivom Met $360^{\circ}$ koji sadrži seriju od 360 video snimaka.

Društvene mreže opisuju grupe veb aplikacija koje u funkciji promocije kulturnog turizma olakšavaju komunikaciju i razmenu preporuka, iskustava i sl. kao i druge turistički relevantne informacije (npr. fotografije i video klipovi) među prijateljima, pratiocima i drugim kontaktima (Sotiriadis \& Van Zil, 2013).

QR kodovi se postavljaju na informativne ploče uz spomenike kulture, a mogu se učitati uz pomoć instalirane aplikacija na mobilnom telefonu. Pored drugih evropskih prestonica i gradova koji su bogati kulturnom baštinom, Beograd će dobiti kodove za 413 spomenika kulture u okviru projekta „Obeležavanje spomenika kulture QR kodovima“. 
Igrice na mobilnim uređajima imaju ulogu u unapređivanju iskustva posetilaca kulturnog nasleđa. Sposobnost mobilnog uređaja da zna da odredi lokaciju na kojoj se nalazi, može pružiti bogato korisničko iskustvo. Na primer, igrica koja koristi lokacije kulturno-istorijskih spomenika može pričati priče korisnicima o bogatoj istoriji i kulturi nekog turističkog mesta. U saradnji sa kustosima muzeja, jedna programerska kompanija razvila je igricu „Beg iz tvrđave“ zasnovanu na lokaciji, koja postavlja igrače oko manje posećenih područja Londonske tvrđave i uključuje ih u živopisnu istoriju kroz kvizove u kojima se susreću neki od najpoznatijih zatvorenika tvrđave.

Promenom motivacije turista, koji su nekada tražili ispunjenje kroz „beg iz svakodnevnog života“ $i$ traženje nečeg različitog, „autentične objekte, kulture i iskustva“, u literaturi o turizmu se pojavio pojam „autentičnosti“. Sam pojam autentičnosti označava verodostojnost, istinitost i jedinstvenost, a najčešće se spominje u kontekstu originalnosti umetničkog dela. Turisti mogu imati drugačije perspektive posmatranja autentičnosti i koristiti različite osobine da bi opisali kulturne proizvode (Cohen 1988). Prema Wang-u (1999) "autentično iskustvo" može biti rezultat različitih izvora. Može slediti iz epistemološkog procesa kada pojedinac prepoznaje npr. objekat kao autentičan. Ukoliko on nema znanje o tome da li je objekat autentičan ili ne onda hipotetički dolazimo do pojma „autentičnog iskustva“. Autentično iskustvo objašnjava Scanell (2001, p. 407) „da je to nešto što je moje, deo mog vlastitog (unutrašnjeg) jaza. Kao takav, to je negovan, nezaboravni aspekt "mene", stvarnog, istinskog i autentičnog". Autentično iskustvo ne može biti preneseno poput informacije, jer ako sam ,ja“ nešto doživeo na sopstveni način ne znači da će i druga osoba doživeti to isto. Pitanje autentičnosti je integralno u kulturnom turizmu, jer turistička mesta, objekti, slike ili ljudi predstavljaju reprezente prošlih događaja, epoha i načina života (Taylor, 2001). Tako se današnja autentičnost izjednačava sa originalom kao prvobitnim konceptom.

\section{METODOLOGIJA ISTRAŽIVANJA}

Globalizacija i razvijanje novih tehnologija pokrenuli su teorijske debate o očuvanju autentičnosti nacionalnih kultura. Ustanove kulture uz pomoć digitalizacije imaju priliku da dopru do svojih posetilaca na jedan nov, „svežiji“ način, da se prikažu posetiocima koji se nalaze van granica matične zemlje ili da se kulturna dobra, koja su preneta u neke druge ustanove, na neki način vrate u digitalnom obliku. Imajući u vidu da Srbija poseduje vredno kulturno nasleđe i da se tek uključuje u proces evropskih integracija kulture koju sprovodi Evropska Unija, tema digitalnih tehnologija koje doprinose valorizaciji kulturnog nasleđa i približavanju najširoj publici, te očuvanju autentičnosti u tom procesu je veoma aktuelna.

Glavni fokus istraživanja je bio na opipljivim kulturnim atrakcijama kao što su muzeji i centri kulturnog nasleđa i na iskustvu njihovih posetioca, jer se na ovim mestima uveliko primenjuju nove komunikacionoinformacione tehnologije za predstavljanje kulture i baštine u digitalnom obliku.

Da bismo ustanovili vezu između digitalnih tehnologija i percepcije autentičnosti kulturnih atrakcija postavili smo sledeća istraživačka pitanja:

1. Koje su osnovne determinante autentične kulturne atrakcije i iskustva?

2. Koja je uloga digitalnih tehnologija u očuvanju autentičnosti?

3. Koja su očekivanja od muzeja i centara kulturnog nasleđa?

Da bismo dobili odgovore na postavljena pitanja sprovedeno je kvalitativno istraživanje među turistima i stručnjacima (kustosima muzeja). Turiste smo podelili u dve fokus grupe i izvršen je intervju u Subotici i Novom Sadu u avgustu 2018. godine. U jednoj fokus grupi je bilo 10 učesnika, a u drugoj 12 učesnika. Razgovori su obavljeni u opuštenoj atmosferi uz obučenog moderatora, a oba intervjua su snimljena kako bi se uradila kasnija analiza. Da bismo dobili jasniji pogled na datu temu od strane stručnjaka, kao sagovornici u dubinskim intervjuima bilo je 8 kustosa muzeja iz Subotice i Novog Sada. Ova studija služi za dobijanje odgovora na pitanja koja se tiču uloge digitalnih tehnologija u predstavljanju bogatstva kulturnog nasleđa, pitanjima autentičnosti i motivima dolaska u ustanove kulture, čulnim iskustvima, zabavnom karakteru koji digitalni mediji mogu pružiti i budućnosti, načinu na koji su prezentovani artefakti i elementima okruženja koji mogu uticati na autentičan doživljaj. 


\section{REZULTATI ISTRAŽIVANJA}

Na osnovu dobijenih odgovora dve grupe ispitanika „posetioci“ $i$ „stručnjaci“ $i$ sprovedene kvalitativne analize došlo se do rezultata koji su prikazani u Tabeli 1.

Tabela 1. Kvalitativna Analiza odgovora posetilaca i stručnjaka

\section{Odgovori posetilaca}

Odgovori stručnjaka

\section{Primena digitalnih tehnologija u promociji muzeja}

- Digitalne tehnologije nude više mogućnosti, imaju interaktivnost, daju više informacija o objektima, podstiču čula, animiraju decu.

- Daju atraktivnost muzejima, posebno 3D prikazi i animacije.

- Što se tiče autentičnosti, digitalne tehnologije ne utiču na nju, a ako se pravilno primenjuju, mogu pojačati iskustvo.

- QR kodovi veoma su korisni, jer povećavaju dubinu i širinu interakcije posetioca sa muzejima.
- Digitalne tehnologije su novo sredstvo za prenos informacija o muzeju, postavkama i sl.

- Digitalne tehnologije se primenjuju za premošćivanje vremena i prostora, kako bi se smanjila složenost ako originalni objekti nisu dostupni.

- Prijemčivost novih tehnologija mladima.

- Problemi se javljaju sa visokim troškovima uvođenja, veliki broj posetilaca pristupa aplikacijama, mogu se javiti tehnički problemi, ažurnost informacija.

\section{Motivi posete muzeja}

- Kulturni motivi, obrazovanje, društveni aspekt, želja da se vidi nešto izuzetno, ambijent - bilo prirodno ili veštačko okruženje, ambijentalne celine i dr.
- Obrazovanje, fizički izgled izložbi, razni specijalni događaji, faktori sredine kao što su boje, prostor, gužva i dr.

\section{Očekivanja}

- Očekivanja od ustanova kulture su čvrsto povezana s autentičnosti: reprodukcija treba biti deklarisana kao takva.

- Dalja očekivanja uključuju način prenošenja znanja i način na koji žele doživeti muzej.

- Učesnici nisu pokazivali zanimanje za zabavu u muzeju, no za njih je važno "kako" je nešto predstavljeno.
- Očekuje se od muzeja da pruži odgovore na pitanja, da obrazuje.

- Deca i omladina imaju očekivanja interaktivnosti I veće upotrebe novih tehnologija u prezentaciji.

- Potrebne su dodatne manifestacije kao što su vođene ture, dobrotvorne priredbe, dečije radionice, predavanja s hranom i vinom, muzičke predstave, pripovedanje, čitanje knjiga i dr.

\section{Načini prezentacije}

- Posetioci najviše vole iskustvo "iz prve ruke“, a zatim i - Postoje tri načina prezentacije: lično iskustvo, vođene da obiđu muzej uz vodiča.

- Prezentacije uz multimedije takođe su veoma popularne. ture i prezentacije uz multimedije, a ključno pitanje je koliko je informacija pruženo i na koji način.

\section{Autentičnost}

- Posetioci nisu sasvim sigurni na šta se odnosi pojam autentičnosti, da li se radi o izložbenom objektu u smislu originalnosti ili autentičnosti iskustva.

- Učesnici su tvrdili da je tumačenje subjektivno i spekulativno pitanje, pa muzej ne može biti autentičan.

- Da bi pojedinac utvrdio autentičnost izložbenih objekata morao bi da ima određena naučna znanja.

\section{Faktori okruženja}

- Za posetioce su veoma važni ambijentalni faktori kao što su dizajn, estetika, temperatura ili osvetljenje.
- Kustosi u autentičnosti vide snagu muzeja.

- Muzeji se prvenstveno vide kao mesta za učenje uz pomoć jedinstvenih "objekata”.

- U nekim objektima poput „Muzeja iluzije“ naglašava se “autentično iskustvo”, a manje naučna istina.

Izvor: Izrada autora

- Veoma se vodi računa o faktorima okruženja koji mogu doprineti da se posetioci osete veoma prijatno i požele da se vrate. 
Nalazi pokazuju da s tačke gledišta posetilaca autentičnost:

1. ima mnoge aspekte i koristi se u različitim kontekstima tj. kao osobina objekta, osobe i kao kvalitet interpretacije,

2. za utvrđivanje autentičnosti moraju da se poseduju određena naučna znanja,

3. i može se smatrati veoma važnom stavkom prilikom posete muzeju. "Autentičnost" je neosvojivi kvalitet objekta/izložbe i digitalni mediji se koriste za pružanje informacija o objektu, što nema uticaja na "autentičnost objekta".

To ima posledice na način na koji posetioci doživljavaju objekt/postavku. Sama izloženost objektima ili postavci muzeja, obično nije dovoljna da garantuje da će ih posetilac doživeti.. Posetioci u većini slučaja nemaju dovoljno znanja i moraju se osloniti na stručnost kustosa. Istovremeno cene digitalne tehnologije, jer im pomažu da bolje razumeju veb sajt kroz dostavljene informacije. Digitalne tehnologije nemaju uticaja na autentičnost nekog objekta, već na način kako se percipira i stoga utiču na kvalitet iskustva korisnika.

Odgovori iz intervjua stručnjaka pokazuju da kustosi muzeja smatraju da je „autentičnost objekta“ neophodna i predstavlja okosnicu muzeja, dok se za kulturne atrakcije, kao što su na primer dvorci, naglasak često stavlja na „autentično iskustvo“. Kustosi smatraju digitalne tehnologije novim alatom koji pomaže u isporuci informacija, ali su naglasili važnost autentičnosti objekta. Većina ih je izrazila vrlo pozitivno gledište o korišćenju raznih mobilnih aplikacija radi privlačenja posetilaca, a naročito pripadnika mlađe populacije. Digitalizovano kulturno nasleđe može se koristiti za održivi razvoj kulturnog turizma. Važan element održivog razvoja kulturnog turizma je ponašanje posetilaca na lokaciji kulturnog nasleđa. Od tehnoloških inovacija ističe se značaj QR kodova, za koja se veruje da povećavaju dubinu i širinu interakcije posetilaca sa nasleđem. Ove nove tehnologije imaju potencijal da prošire dostupnost i širenje informacija o kolekcijama i eksponatima muzeja. Kustosi su istakli važnost ambijentalnih faktora, jer su posetioci postali zahtevniji i traže različite stilove prezentacije. Kustosi i menadžeri kulturnih atrakcija pokušavaju pronaći način na koji mogu privući posetioce, ali su isto tako izrazili potrebu za profesionalizmom u prezentaciji sadržaja.

\section{ZAKLJUČAK}

Digitalni alati sve više postaju integralni element komunikacije između kulturnih atrakcija i posetilaca. Imajući u vidu da je proces digitalizacije veoma aktuelan i u Srbiji, u uvom radu smo predstavili teorijsku osnovu digitalnih tehnologija u funkciji promocije kulturnog nasleđa i autentičnosti, gde smo ukazali na razliku između „autentičnosti objekta“ $i$,autentičnog iskustva“. $U$ svrhu dublje analize teorijskih koncepata urađeno je istraživanje među posetiocima i stručnjacima, koje je pokazalo kako se digitalne tehnologije mogu primeniti u promociji kulturnih atrakcija, koji su motivi posete i očekivanja prema objektima kulturnog nasleđa i načine prezentacije kulturnog sadržaja.

Digitalne tehnologije potpomažu uspostavljanje odnosa sa posetiocima kulturnih atrakcija, prenoseći informaciju na interesantan i zabavan način. Neke od najvažnijih osobina digitalnih tehnologija su interaktivnost, personalizovani pristup i prevazilaženje vremenskih i prostornih barijera. Što se tiče interaktivnosti postoje dva različita nivoa. Na osnovnom nivou interakcija može značiti dobijanje informacija pritiskom na dugme, kao što je slučaj s internetom ili mobilnim aplikacijama. Na višem nivou nalazi se virtuelna stvarnost u kojoj korisnik igra aktivnu ulogu i postaje sastavni deo virtuelnog sveta. Virtuelni muzeji stvaraju prostor za izlaganje dela kada nema fizičkog sveta, a nova dimenzija povezivanje ljudi sa kulturnim atrakcijama odvija se kroz virtuelne igrice. Posebno su mlađi posetioci zainteresovani za korišćenje novih tehnologija prilikom obilaska kulturnih atrakcija.

Problemi na koje se može naići prilikom korišćenja digitalnih tehnologija ogledaju se u visokim troškovima uvođenja, velikom broju poseta na sajtu ili aplikaciji, mogu se javiti tehnički problemi, opasnost od upada u virtuelni prostor, problemi sa ažurnošću informacija i dr.

Primena digitalnih alata otvara pitanje očuvanja autentičnosti. Međutim, potrebno je razlikovati digitalne tehnologije koje se koriste za tumačenje stvarnog objekta ili za prikaz objekata u njihovim digitalnim formama i simulacijama. U situacijama kada su prikazi dobro tehnički urađeni, primaoci informacija mogu uzeti objekte na ekranu kao prave, autentične, iako predstavljaju manipulaciju stvarnosti. Takve simulacije, poput 3D 
prikaza, holograma ili virtualne stvarnosti, pružaju tzv. „kvazi“ autentična iskustva kako napreduje tehnologija. Kustosi se pribojavaju da bi ove opsene slike mogle da zadovolje znatiželju i da potencijalni posetioci umesto da dođu u muzej i sve pogledaju uživo, posetu izvrše radije „virtuelno“. Ispitanici su istakli da se mnogi od današnjih muzeja suočavaju sa ekonomskom dilemom i pokušavaju da pronađu rešenje kroz prilagođavanje zahtevima savremenih potrošača uz sve veću podršku savremenih digitalnih tehnologija.

S obzirom na prethodne konstatacije, da se digitalne tehnologije mogu smatrati vrednim alatima za pružanje dodatnih informacija preko ekrana (mobilni telefon, monitor ili tablet), možemo reći da podupiru autentično iskustvo kulturnog nasleđa.

\section{LITERATURA}

Cohen, E. (1988). Authenticity and commoditization in tourism. Annals of Tourism Research, Volume(3), 371386. DOI:10.1016/0160-7383(88)90028-X

Di Pietro, L., Guglielmetti Mugion, R., Mattia, G., \& Renzi, M. F. (2015). Cultural heritage and consumer behaviour: A survey on Italian cultural visitors. Journal of Cultural Heritage Management and Sustainable Development, 5(1), 61-81. DOI:10.1108/JCHMSD-03-2013-0009

Richards, G. (2002). From Cultural Tourism to Creative Tourism: European Perspectives. Tourism, 50 (3), 225234. DOI:10.1079/9780851994406.0003

Richards, G. (1996). Cultural Tourism in Europe. Wallingford: CABI

Russo, A.P., Verbeke, M., \& Priestley G.K. (2008). Cultural Resources for Tourism. New York: Nova Science Publishers.

Scanell, P. (2001). Authenticity and Experience. Discourse Studies, 3(4),405-411. DOI:10.1177/146144560100 3004005

Seppe, M., \& DiTrapani, G. (2010). Cultural tourism and creative regeneration: Two case studies, International Journal of Culture Tourism and Hospitality Research, 4(3), 214-227. DOI:10.1108/17506181011067600

Smith, C. (2014). (Re)Engineering Cultural Heritage Context Using Creative Human Computer Interaction Techniques and Mixed Reality Methodologies. Advanced Research and Trends in New Technologies, Software, Human-Computer Interaction, and Communicability, 441-445. DOI: 10.4018/978-1-4666-6543-9. ch086

Sotiriadis, M.D., \& van Zyl, C. (2013). Electronic word-of-mouth and online reviews in tourism services: the use of twitter by tourists. Electronic Commerce Research, 13(1), 103-124. DOI: 10.1007/s10660-013-9108-1

Taylor, J. P. (2001). Authenticity and sincerity in tourism. Annals of Tourism Research, 28(1), 7-26. DOI:10.1016/ S0160-7383(00)00004-9

Thomas, M., Selsjord, M., \& Zimmer, R. (2010). Museum or Mausoleum? Electronic Shock Therapy. Digital Culture and E-Tourism: Technologies, Applications and Management Approaches, Vol. 3, 10-34. DOI:10. 4018/978-1-61520-867-8.ch002

Wang, D. (1999). Rethinking Authenticity in Tourism Experience. Annals of Tourism Research 26(2), 349-370. DOI:10.1016/S0160-7383(98)00103-0

Whyte, B., Hood, T., \& White, B. (2012). Cultural and Heritage Tourism: A Handbook for Community Champions. Ottawa: Federal Provincial Territorial Ministers of Culture and Heritage.

UNESCO (2015). What is meant by "cultural heritage"? Retrieved Avgust, 2018 from http://www.unesco.org/ new/en/culture/themes/illicit-trafficking-of-cultural-property/unesco-databaseof-national-cultural-heritage-laws/frequently-asked-questions/definition-of-the-cultural-heritage/ 


\title{
PRESERVING THE AUTHENTICITY OF CULTURAL HERITAGE IN THE PROCESS OF DIGITIZATION
}

\begin{abstract}
:
There is an increasing number of museums and cultural attractions that use digital technologies as a platform for providing information on localities and cultural heritage. The first contact of a contemporary visitor with a cultural heritage is via the Internet. Applications such as mobile phone systems, travel planners, web portals, and 3D applications support consumer experience by a way of a visit. In addition, mobile and 3D applications facilitate for users to understand complex cultural phenomena through learning with fun involved. The paper explores the connection between the process of digitization of cultural heritage and how to preserve authenticity. The authenticity of digital heritage refers to the reliability of the datas and the quality of therepresented content. Digital technologies can affect the quality of information transfer and for this reason, qualitative research has been initiated through interviews with experts regarding the authenticity of the facility with respect to the digitization carried out. The results of the research have shown that the authenticity of cultural heritage in the process of digitization is very important from the perspective of the curator of the museum.

\section{Keywords:}

cultural heritage, digital technologies, authenticity, virtual museum, mobile applications
\end{abstract}

